\title{
Empowerment for Participation: Measuring Motivation, Stress, Defense Routines and Engagement
}

\author{
Clive Michelsen (1) \\ Center for Research and Development, Sciens College, Malmö, Sweden \\ Email: clive.michelsen@sciensecollege.se
}

How to cite this paper: Michelsen, C. (2021). Empowerment for Participation: Measuring Motivation, Stress, Defense Routines and Engagement. Psychology, 12, 511-535. https://doi.org/10.4236/psych.2021.124032

Received: February 28, 2021

Accepted: April 12, 2021

Published: April 15, 2021

Copyright $\odot 2021$ by author(s) and Scientific Research Publishing Inc. This work is licensed under the Creative Commons Attribution International License (CC BY 4.0).

http://creativecommons.org/licenses/by/4.0/

\begin{abstract}
Background: There has been increased attention in concepts such as meaning, self-care, work-life balance and others designed to address human sustainability in the workplace. Nonetheless, world-wide per capita increase in psychological related sick-leave costs companies approximately $\$ 748$ Billion annually? Approximately 55\% of company sick leave is psychosocial related and this is increasing annually. Finding the necessary tools to identify predictors related to psychological safety and ill-health is now more critical than ever before. Furthermore, increasing awareness and reducing the disconnection between an individual's situational wellbeing and an organization's need for productivity is paramount. Currently, corporate mental health consists of symptomatic related solutions. Unfortunately, these retroactive models are usually short-lived plasters. Objective: This study aims to present reliability and validity of the Empowerment for Participation (EFP) batch of assessments and its methodology to measure, predict and proactively monitor an individual's mental health and wellbeing. The study will also briefly introduce three risk assessments: Risk for Burnout, Risk of Anxiety and Risk for Depression, as well as an employee Engagement Potential measure. Study Design, Setting and Method: The EFP batch of assessments, consists of 110 questions. They are used to measure employee motivation, stress, defense routines and motivational positioning (situational adaptiveness) on an individual and aggregate level within a company. This study looks at the reliability and validity of the EFP batch to effectively measure the sustainability or status of an individual in relation to their engagement potential, wellbeing, adaptability, potential risk for burnout, anxiety, and depression. A cohort from four small companies and several unbound individuals (employed but not belonging to the four companies) were included in this study. An empirical design using raw EFP psychometric data to measure value consistency
\end{abstract}


correlated to anti-depressive prescription use or any related diagnosis was used. Results: Reliability and validity results for EFP batch of assessments (N = 73) were analyzed using Cronbach's Alpha for internal consistency: Motivation (Items $=20, \alpha=0.939$ ), Stress (Items $=20, \alpha=0.887$ ), Defense Routines (Items $=20, \alpha=0.870)$, and PMP (Items $=50, \alpha=0.944)$. Discriminant analysis was used on the four risk assessments (extracted from 110 EFP questions) and showed excellent results: Risk for Burnout ( $\alpha=0.928, p<0.001$, Partial Eta Squared $=0.900$, Cohen's d =0.900), Risk for Anxiety $(\alpha=0.864, p$ $<0.001$, Partial Eta Squared $=0.885$, Cohen's $d=0.885)$, Risk of Depression $(\alpha=0.798, p<0.001$, Partial Eta Squared $=0.788$, Cohen's $d=0.787)$. Engagement Potential $(\alpha=0.959, \mathrm{M}=3.849, \mathrm{SD}=0.967, \mathrm{Var}=0.935)$ is calculated from the mean of means from the Burnout, Anxiety and Depression values. External validity showed $>0.885$. Conclusion: This original study suggests that EFP Batch of Psychometrics and the subsequent derivate risk assessment reports have excellent reliability and validity. Diagnosis is not the primary objective, but rather to highlight a tool that can be used for proactive engagement with employees, and to introduce a sustainable psychosocial wellbeing methodology for employee psychological safety. The purpose of which is to assist individuals in improving their situational self-awareness and to manage their personal situational environments sustainably. As a mental health tool to identify and prevent psychosocial illnesses proactively, the EFP batch produces consistently reliable results to serve as both a diagnosis and counseling tool worthy of major research in the future.

\section{Keywords}

Risk for Burnout, Risk of Anxiety, Risk for Depression, Occupational Health, Presenteeism, Work-Related Stress, Psychosocial Risk Factors, Sickness Presence, Work-Family Conflict, Workload, and Presenteeism

\section{Introduction and Background}

Environmental Health and Occupational Health Safety (EHS \& OHS) have two major things in common; they are both tasked with keeping company staff healthy, both physically and mentally. Contaminants and contagions are not limited to biological or chemical exposures, with specific measures and values, but they also include psychosocial factors affecting employee sustainability, psychological safety, teamwork, productivity, engagement, and wellbeing.

Historically, when it comes to employee health, companies have primarily focused on practical physical exams such as a blood analysis, EKGs, and drug testing, etc. Occupational Safety and leadership strategies have predominately focused on 5S, LEAN and quantifiably related efficiencies. Both have also been ignoring two of the most fundamental causes of workplace accidents and sick leave, for example, mental ill-health in the workplace, time pressure and psychological safety (Michelsen \& Thorsteinsdottir, 2010). Left in the shadows, 
psychological safety and employee wellbeing have taken second fiddle to short-term economic benefits. As a result, presenteeism costs (Deloitte, 2020) have skyrocketed and are expected to cost employees approximately $£ 44 \mathrm{~B}$ in England alone this year. Presenteeism should not be confused with sick leave as it relates to those that choose to remain at work, even though they are not well, thereby impacting productivity and the bottom line.

In the modern industrialized world, where time and space have imploded, performance gains are no longer realized through efficacy, but rather through productivity achieved through innovation, creativity \& psychological safety (Michelsen, 2008). As these strategic advantages become more evident, companies arbitrarily rush to implement ineffective or retroactive treatment models to address these needs.

The World Bank and World Health Organization United suggest that mental health should be a priority as costs are estimated to reach $\$ 1.670$ trillion annually (Mnookin, 2016). Prior to the COVID-19 pandemic, global employment is estimated at 44\% (ILO-International Labor Organization, 2020) of the population suggesting that mental health costs companies about $\$ 738$ billion annually, excluding presenteeism. In the UK, a sixth of all workers are experiencing a mental health problem at any one time (McManus et al., 2016), which is thought to be responsible for almost half of working days lost in Britain (HSE, 2019) and more than $50 \%$ of sick leave days in Sweden (Skandia, 2019).

A Belgium study of 2983 workers (Janssens, Clays, de Clercq et al., 2016) found a $(50.6 \%)$ prevalence of presenteeism correlated to high job demands, high efforts, low support, and low rewards. Furthermore, a significant association could be observed for both bullying and work-to-home conflict in relation to presenteeism. Their study showed that presenteeism is not purely driven by the health status of a worker, but that psychosocial work characteristics play a role too. In a National Health Services study consisting of 156,951 employees, they found that there was a low-to-moderate negative correlation between presenteeism and staff engagement. This study also concluded that putting pressure on health-care staff to come to work when unwell is associated with poorer staff engagement (Admasachew \& Dawson, 2011).

Measuring presenteeism will provide more accurate information about employee health (Kinman, 2019). Therefore, raising awareness to the many risks of working while sick and the economic, moral, cultural, and social pressures is important for all stakeholders. Finding a workable and sustainable solution that can proactively monitor and positively impact mental health, increase engagement and productivity will ultimately stimulate boardrooms to action. Systemic evidence-based interventions to identify and manage presenteeism are therefore needed (Kinman, 2019).

\section{Engagement, Presenteeism and Well-Being}

Engagement, presenteeism and well-being have all been linked to performance 
and productivity (Skagen \& Collins, 2016). A Business in the Community study (BITC, 2019) has shown that work-related mental health problems are caused largely by increased pressure (52\%) and workload (36\%), lack of support (35\%), negative work relationships (33\%), lack of trust (33\%), poorly handled organizational change initiatives (33\%), feeling underpaid (28\%), lack of control (29\%) amongst others. In a meta-analysis study done by Israel et al. (1996), a conceptual framework was constructed that identified various principles for an effective and preventive way to intercede in occupational health to reduce stress and to improve safety. They examined specific implications of the model for the development of prevention interventions (e.g., context-specific interventions and primary, secondary, and tertiary prevention). These included prevention interventions that addressed aspects related to environmental, ergonomic, and psychosocial stressors and a combination of physical-environmental and psychosocial stressors.

A meta-analysis carried out by Duijts et al. (2007) showed that predictors of sickness can be used in a homogeneous manner to identify presenteeism. In a literature review they also revealed that key work factors associated with psychological ill-health and absence in staff were associated with long hours worked, work overload and pressure, lack of control over work, lack of participation in decision making, poor social support, and unclear management and work role.

In a study by Michie \& Williams (2003) evidence showed that sickness absence was associated with poor management style. "Successful interventions that improved psychological health and levels of sickness absence used training and organizational approaches to increase participation in decision making and problem solving, increase support and feedback, and improve communication." They concluded that many of the work-related variables associated with high levels of psychological ill-health were potentially amenable to change. "Intervention studies that have successfully improved psychological health also reduced sickness absence." (Michie \& Williams, 2003)

In an article published in the American Journal of Industrial Medicine, Cahill concluded that attention to psychosocial hazards in work environments is an important component of occupational safety and health interventions. The report linked several measurable psychosocial characteristics with negative psychological and physiological consequences that resulted in serious mental and physical health connections. The report concluded that intervention strategies to reduce psychosocial stressors should include assessments to measure psychosocial changes within the sometimes-contradictory organizational framework (Cahill, 1996).

The role of top management to be involved in supporting solutions to increase engagement and interventions to prevent psychosocial burdens in organizations is critical (Israel et al., 1996). If policy makers and employers are to take health issues into account, when making decisions that will have an impact on work practices and work environments, they will need accurate information concern- 
ing the impact change they have on psychosocial working conditions and health status. The necessity for accurate assessments to measure change in psychosocial working conditions that can focus on the collection of data at baseline and a single follow-up time point is needed (Smith \& Beaton, 2008).

There have been many complex attempts to measure performance, engagement, and well-being in the workplace over the years. These include but are not limited to assessments for: Job Satisfaction and Performance (Williams \& Anderson, 1991), Development of a Measure of Workplace Deviance (Bennett \& Robinson, 2000), the World Health Organization's Health and Work Performance Questionnaire (Kessler et al., 2003), The Stanford Presenteeism Scale (Collins et al., 2005), the Utrecht Work Engagement Scale (Schaufeli, 2002), and others. It could be argued that potential weaknesses exist with static measures since they are usually fixed in time. Static measures lack historical, mean deviation changes for both individuals and group variances and have limited comparisons to individual and group risk distributions. One can argue that since life is in continual movement, a measure should be able to measure that movement as the individual interprets it. Moreover, continuity in understanding an individual's interpretation of their situational environment could provide therapists and leaders with the ability to proactively address deviations using acceptable prevention methods. According to Michelsen (2008), a reliable and valid methodology to support individual psychological safety and engagement needs continuity in its construct. By that he suggests that individual measures need to have the ability to monitor individuals within their environment, overtime, and dynamically showing deviations, mean scores and trends covering a broad spectrum of issues that affect psychological wellbeing, engagement, and participation in a myriad of situations.

The correlations between engagement, presenteeism and psychological wellbeing are increasingly recognized as significant today (Salvagioni et al., 2017). Nonetheless, sustainable long-term employee health is less understood, and to date, there is little empirical evidence to support a hypothesis. The aim of this report is to present a summary of the EFP batch of assessments, in a broad context, prove its reliability, validity and capacity to track employee health and situational and psychological safety by providing current, historical, mean and deviation results overtime.

\section{EFP Battery of Assessments}

The EFP assessments consist of 110 questions that measure individual motivation, stress, defense routines, and perpetual motivation positioning or adaptability in seven environments (knowledge, external demands, social, health \& safety, self-expectancy, openness, and self-esteem) to gain a composite understanding of how an individual feels within their situational environment and their ability to engage (Michelsen, 2008, 2019; Michelsen \& Thorsteinsdottir, 2010).

The EFP batch of assessments was developed in 2001 by JAC International's 
Modern Management Consulting. Originally used as a "Change Management" tool to measure employee psycho-social wellness prior to, during and after Transformational Change projects within organizations. Initially in paper format, it transformed into a digital online version in 2008, using html. In the advent of Skype and other online media service providers, face-to-face feedback was provided to all assessed individuals. After years of upgrades and development the EFP measure could be used to monitor Employee Psychological Wellbeing within an online platform, both securely and effectively. The internet pathed the way for a remote multi-modal ecosystem where individuals could meet with a caregiver or a caregiver team (multi-modal team of specialists).

The EFP measures, predicts, and proactively monitors individual psychological wellbeing. According to Baumark (2004), this has a direct and positive impact on employee's performance and productivity. Baumruk (2004) also emphasizes that employee engagement is the most powerful factor to measure a company's vigor. The EFP assessment assesses an individual's current wellbeing and mental health status (stress, burnout, anxiety, and depression). Furthermore, the EFP identifies various factors called engagement killers that contribute to a lack of meaning. This can include limitations to personal growth opportunities or unreasonable expectations, poor communication (lack of feedback, uncertainty regarding objectives, priorities, and workflow), tense and conflictual working environment and many more.

The Motivation assessment measures several personalities and behavioral traits such as: transparency (openness), teamwork, creativity, stimulation, self-esteem, and participation amongst others. The Stress assessment measures several stress traits and symptoms such as: communication, knowledge, conflict, justice, safety, and health at work. The Defense Routine assessment measures the ability to participate in an effective and open manner. Defense routines are habits that have been added to protect us from threats to our self-image and identity. The test aims to measure the levels of these routines in areas such as guilt, flexibility, participation, forgiveness, communication, conflict, control, and rationality. The Perpetual Motivation Positioning (PMP) consists of seven subscales, namely 1) competence, 2) external requirements, 3) social relationships, 4) psychological challenges, 5) expectations of self, 6) trust and 7) self-esteem. The purpose of the test is to gain in-depth insights into an individual's experiences of boundaries and participation, trust, creativity, and openness.

Anhita (2014) identified: workplace wellbeing, organizational policies, compensation, training and career development, teamwork and co-workers, leadership, and the working environment as key levers to employee engagement. The EFP batch which includes the Perpetual Motivation Positioning (PMP) assessment addresses all these identified areas.

The PMP assessment questionnaire is a series of 50 questions that are situational-based and connected to scientifically established methods (psychological, business leadership models and the DSM V). The PMP assessment is supported 
by three independent questionnaires comprising of 20 questions each (stress, defense routines and motivation).

Balancing PMP. A person's balance and performance are, by product, the sum and uniformity of their universal PMP environment. Low PMPs cause tension and stress and if left unabated this stress will subsequently produce physical symptoms and behavioral changes (Michelsen, 2008). The Process Theory of Perpetual Motivation Positioning (PMP) is a theory with its core beliefs somewhere between various motivation theorists, with their focus on needs, and post-modernist theorists, with their focus on identity construction or the self. PMP puts context into the leadership of the situational environment by looking at seven fluctuating variables facing the individual (Michelsen, 2008). The theory shows how a low PMP environment will affect individual participation, motivation, subjectification (Alvesson, 2004) and other identity constructions. Naturally, the changing situational environment confronting the individual is a major factor. As the organism metaphor in Morgan's book Images of an Organization (1997: p. 386) implies additional reflection into relevant parameters are necessary. This reflection should consider the interconnectedness of the PMP variables to the situational environment, motivation, and identity theories to maximize understanding.

The EFP variables in turn are actionable, interconnected constructs that affect an individual's situational understanding and the negotiation to effectively participate within various contexts. Since the assessments are situationally based and interpreted by the individual within his/her own context thereby meeting the needs of the changing environment.

Burnout assessment measures the risk for burnout within the company. Burnout emerges when the demands of a job outstrip a person's ability to cope with stress, compiled from World Health Organization's guidelines for burnout diagnostic code: ICD-10-CM Diagnostics code Z73.0.

General Anxiety Disorder (GAD) measures the risk for anxiety, offering an indication as to whether the person is experiencing the most common symptoms of an anxiety disorder, such as: excessive worrying, agitation, restlessness, fatigue, difficulty concentrating, irritability etc. compiled from World Health Organization's guidelines for anxiety diagnostic code: ICD-10-CM Diagnosis Code F41.1.

Depression assessment measures the risk for depression. Depression symptoms are related to work absences and impaired work performance, even more work stressors add to this impact, compiled from World Health Organization's guidelines for depression diagnostic code: ICD-10-CM Diagnosis Code F32.9.

To avoid psychological and central tendencies and to increase reliability and validity of the EFP measure, several measures are taken. Firstly, individuals taking the assessments are not asked to take strict symptomatic related questions when looking for specific diagnoses but rather, they are asked to take the assessments regarding their general wellbeing and how they feel within their situa- 
tional environment. Secondly, all questions are visual analog scales (VAS).

Derivative reports (compiled from the 110 EFP questions) include, 1) a Risk for Burnout with four subcategories related to symptoms (physical and psychological), depersonalization, self-expectancy, and external demands, 2) a Risk for General Anxiety, 3) a Risk for Depression, and 4) Engagement Potential. All four derivative measures are dependent upon completion of the four EFP assessments as they are extracted and complied therefrom, however, only a brief analysis will be provided within the framework of this study.

\section{The Present Study}

This study is part of a broader project investigating workplace presenteeism, psychological wellbeing, engagement and proactive tools and measures to lessen harmful psychosocial effects inhibiting productive and sustainable working lives. The reliability and validity of this report connects the theoretical constructs of proposition to logical variance distribution providing meaning and relevance to the relationship between the measurable variables of those constructs.

The aim of this study is to collect, analyze and disseminate accurate and comprehensive information on the reliability and validity of the EFP as a measure to proactively monitor and proactively sustain engagement, prevent psychosocial related ill-health, presenteeism and sick leave.

Prediction requires only correlations, but in contract, explanations require causations. Given the importance of environmental variables and continuity, this study will also examine whether there are any gender and age bivariate convergencies or divergencies. The reliability and validity of the distribution risks will assist to construct correlations between the various EFP conclusions and the understanding of identified cause-effect relationships. This paper reports the results from four Swedish companies within a certified Company Healthcare and Rehabilitation provider in Sweden. The four companies studied herein prided themselves on the health and wellbeing of their employees.

The study specifically examines the internal consistency and homogeneity of the EFP battery of assessments, its reliability and construct validity.

All the EFP batch of assessments were taken by company employees and obligatory feedback was provided by trained psychologists and healthcare coaches. All the participants received feedback, and a vast majority of them $(95.89 \%)$ validated their scores and confirmed their findings.

\section{Method}

\subsection{Participants}

Employees from four companies and three from an unbound category $(\mathrm{N}=73$, $\mathrm{SD}=0.501$, Mean $=1.55$ ) participated in this study (an employee not bound to a specific company falls into an unbound category). Ages ranged from 26 to 69 (M $=44.67, \mathrm{SD}=10.269)($ Figure 1$)$.

The study consisted of 33 males $($ Percent $=45.2)$ and 40 females $($ Percent $=$ 
54.8) with a $\mathrm{SD}=0.501$ and $\mathrm{M}=1.56$ suggesting excellent homogeneity. At the time of their assessment, employees had been working at their specific positions from 6 months to 15 years. However, a counselor did forget to ask three individuals the internal validation questions. Some employees had taken the assessments multiple times or on a quarterly basis during the assessment period.

\subsection{Instruments}

Originally designed in early 2001, as a psychological status monitoring tool used to assess employees undergoing transformational change initiatives within their companies (Michelsen, 2008), the EFP battery has seen numerous upgrades from its original paper format to a digital (html) version in 2007 to the fully interactive online ecosystem used today. For psychometric assessments to achieve their full potential, individual integrity, privacy, and a framework for honesty and trust are paramount in achieving reliability and validity. For this reason, an online ecosystem needs to provide psychological safety where individuals can feel safe, access an encrypted "Private Space" (Figure 2) and receive feedback or support if or when needed.

The EFP batch is accessed via an online ecosystem designed to proactively support an individual in their eHealth needs. Here individuals can connect with their Coach, Caregiver, Doctor or Psychologist, complete their psychometrics (as needed or at least on a quarterly basis, not being too intrusive or missing seasonal fluctuations) and receive live feedback about their results. All communication is encrypted and done within a (HIPAA \& GDRP compliant) secure framework respecting individual integrity. Identified deviations can be addressed early together with the caregiver or a certified counselor using the inbuilt Cognitive Behavioral Therapy (CBT) framework.

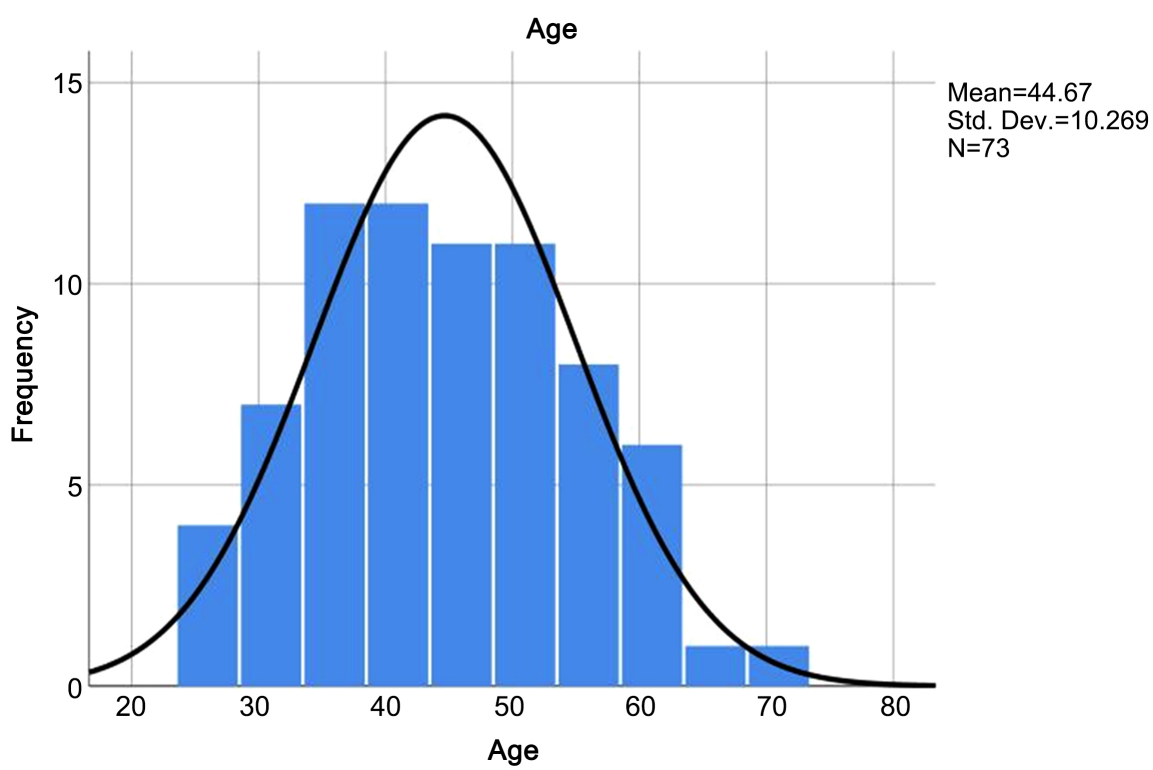

Figure 1. A distribution curve and histogram showing age frequency and homogeneity for $\mathrm{N}=73$. 


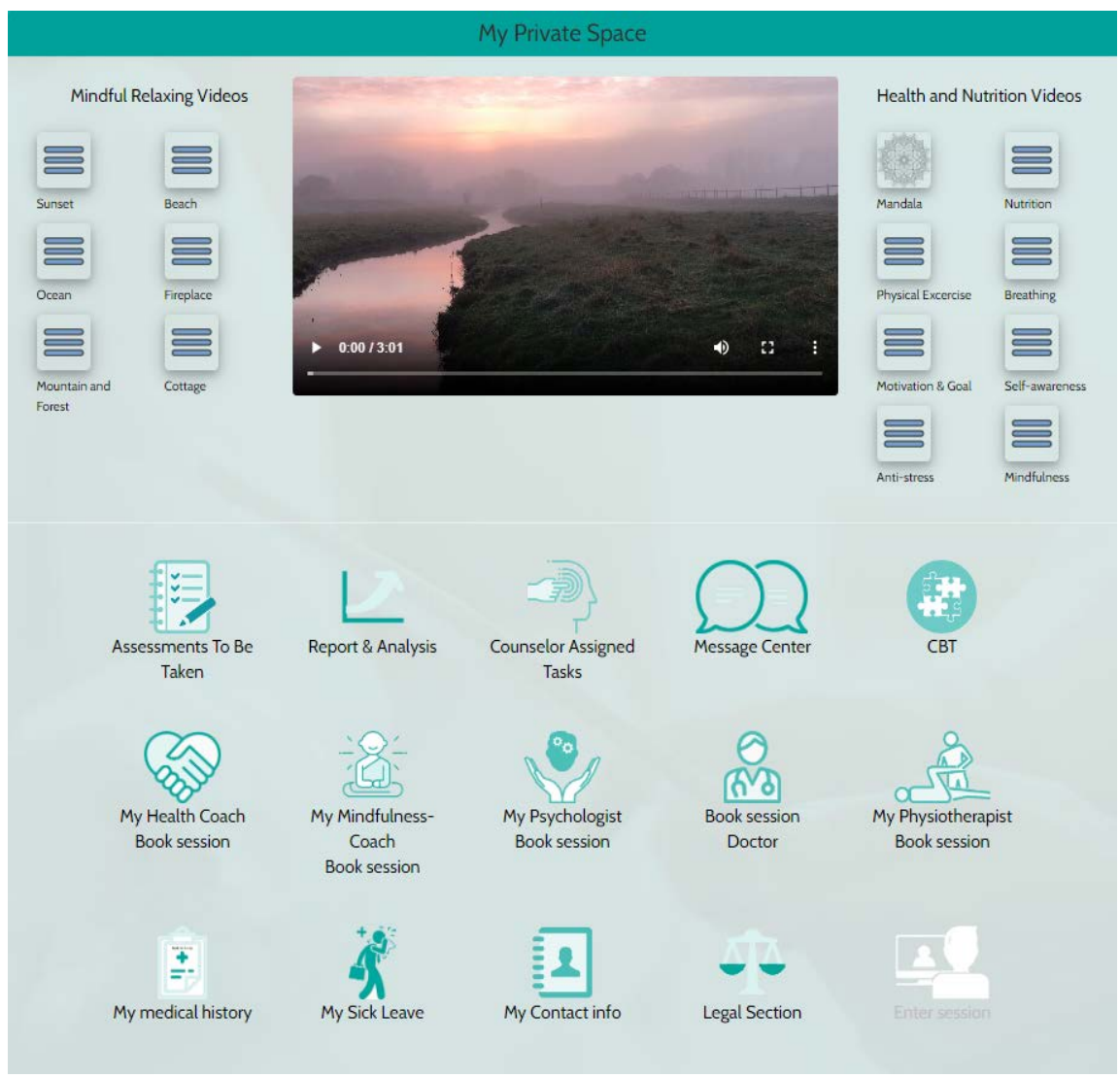

Figure 2. Shows the SaaS-based, HIPAA compliant, online ecosystem used by employees to monitor their psychological wellbeing proactively. Since the platform is a SaaS-based product, coaches, counselors, insurance companies and Preventive Medicine can actively provide assessment feedback. Individuals can get access to additional support services if desired or contracted. The EFP batch of assessments is taken under the "Assessments To Be Taken" icon. Feedback is usually provided by an individually assigned Health Coach or Psychologist. Employees also can monitor their own results under the "Report \& Analysis" icon.

The EFP assessment battery consists of four (4) assessments plus a 360-degree feedback assessment when objective feedback is needed (not addressed herein). All assessments are scored using Visual Analog Scales (VAS), consisting of a straight line with a beginning and end point, for example, Very Good - Very Poor (Figure 3). As the slider moves from left to right, the text positioned at either end of the line increases as the opposite end decreases. The position where the slider stops is represented by a number from $0-20$. The slider can be moved in either direction or in accordance with how the assessed feels in regard to that specific question. To minimize clustering of points around a preferred numeric value or description as used by Likert-type assessment scales, no visible numeric values or intermediate points are visible or seen by the assessed. The Journal of Behavior Therapy and Experimental Psychiatry showed that VAS-A scales used below enable simple and rapid assessment of state of anxiety and exhibit superior psychometric properties (Abend et al., 2014). 


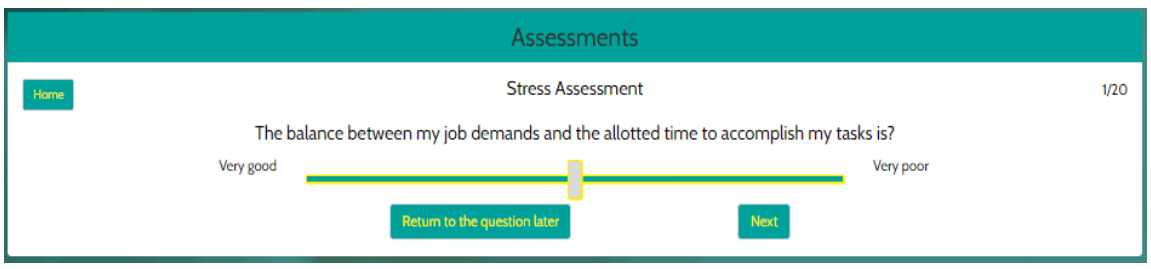

Figure 3. Shows an EFP assessment question using a VAS line with hidden values to minimize cluster tendencies. The button can be moved in either direction, either left or right based-upon how an individual may feel and the scale variables increase/decrease proportionally.

Figures 4-6, and Figure 7 represent a lineal scale shown to the assessed employee during their feedback session. The vertical $y$-axis represents the questions, and the $\mathrm{x}$-axis represents the score from 0 - 20. A lineal cure representing the scores for each question is correlated to the previous and historical mean curves. Deviations can be immediately identified and are addressed during the follow-up feedback session. The blue line represents the historical mean (suggesting that historically this person had very low motivational levels. The green line represents the previous score curve and the red line represents the current scores. A total numerical value for the current score is shown in the text above the lineal graph and in the speedo-gram gauge on the right thereof.

The EFP assessment batch consists of four separate assessments, namely the:

\section{Motivation Assessment-MA Assessment}

The assessment consists of 20 VAS-questions and aims to show at what level the individual's motivation lies. It measures the individual's motivation in areas such as transparency (openness), meaning, identification, balance, teamwork, stimulation, self-esteem, participation, and engagement amongst others.

Stress Assessment-SA Assessment

The assessment consists of 20 VAS-questions and aims to show at what level the individual's stress level by measuring several stressors and symptoms in areas such as communication, knowledge, conflict, justice, values, safety, and health in the workplace.

Defense Routines Assessment-DA Assessment

The assessment consists of 20 VAS-questions. The purpose here is to get a mapping and understanding of an individual's defense routines and the ability to participate effectively and openly. The concept of defense mechanism drives from Freud (Freud, 1923) where more difficult-to-handle associations are considered to exist in the so-called primary process (subconscious process), usually considered as an antagonistic relation to the secondary process (conscious processes). Rather herein, the DA Assessment uses Neisser's redefinition (1967) of these processes, where they are not perceived as antagonistic but instead as essential to each other. This suggests that the secondary process is given opportunities to process primary material through an appreciation of the routines that the individual creates as a defense. According to Senge (1990) and Michelsen \& Thorsteinsdottir (2010), defense routines are habits created to protect us from threats to our self-image and 
identity. Therefore, these routines provide protection for our deepest assumptions. The DA assessment aims to measure these routines in areas such as guilt, flexibility, forgiveness, communication, conflict, control, and rationality.

Perpetual Motivation Positioning-PMP Assessment

The assessment consists of 50 VAS-questions, divided into seven sub-scales, namely 1) knowledge, 2) external demands, 3) social environment, 4) health \& safety, 5) self-expectations, 6) openness, and 7) self-esteem. The assessment is presented in a visual spider-gram for easy visual identification of areas in conflict. For example, deviations or anomalies with the external demands, self-expectations and social environments are usually associated with those persons exhibiting psychological challenges or some degree of burnout. The purpose of the assessment is to gain an insight into a person's boundaries, participation and adaptability, trust, creativity, openness and more.

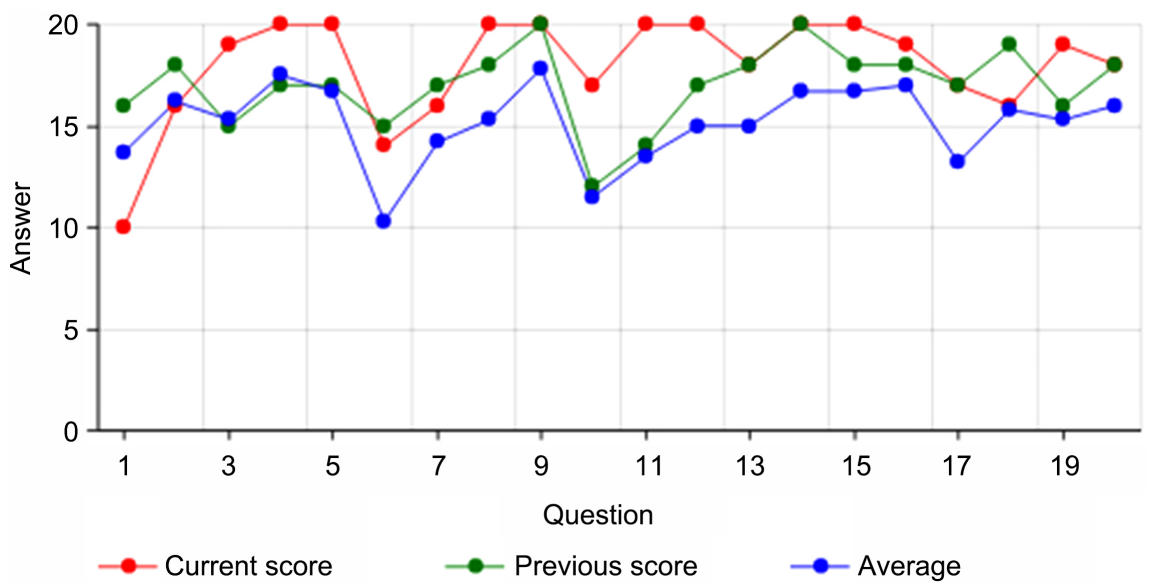

Figure 4. The scale illustrates the degree of motivation by an employee. $(0-100)=$ Very Low Motivation, $(101-200)=$ Low Motivation, $(201-300)$ = Average Motivation, $(301$ 371) $=$ Motivated, $(371-400)=$ Highly Motivated.

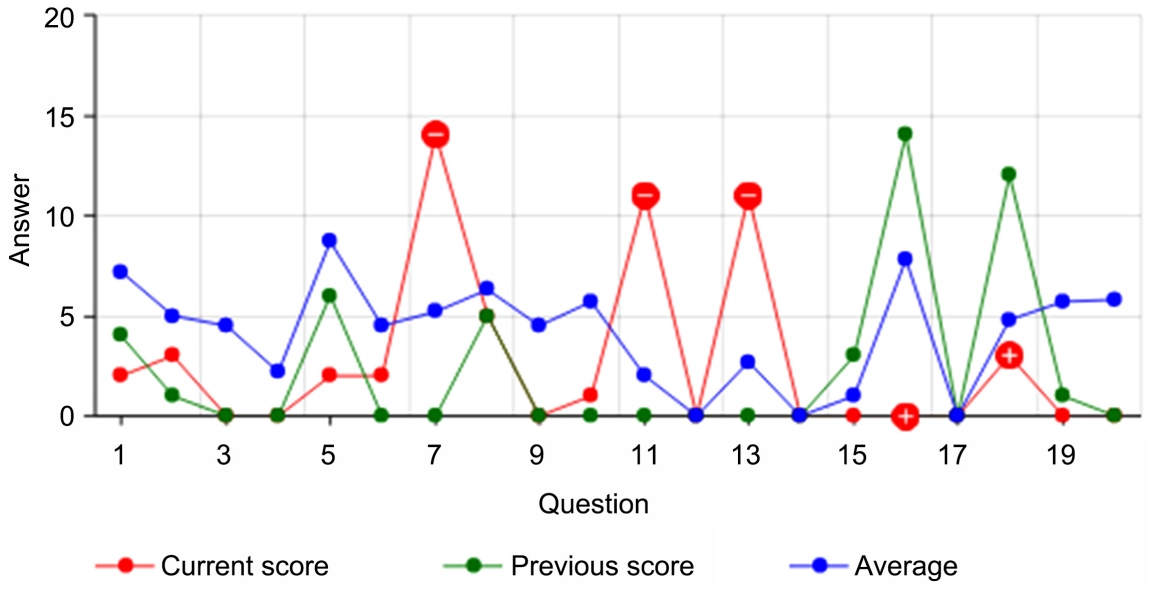

Figure 5. Stress graphic representing a numerical value (current \& historical) on a scale illustrating the degree of Stress by an employee. $(0-100)=$ Very Low Stress, $(101-200)=$ Low Stress, $(201-300)=$ Moderate Stress, $(301-371)=$ High Stress, and $(371-400)=$ Extremely High (Stressed). 


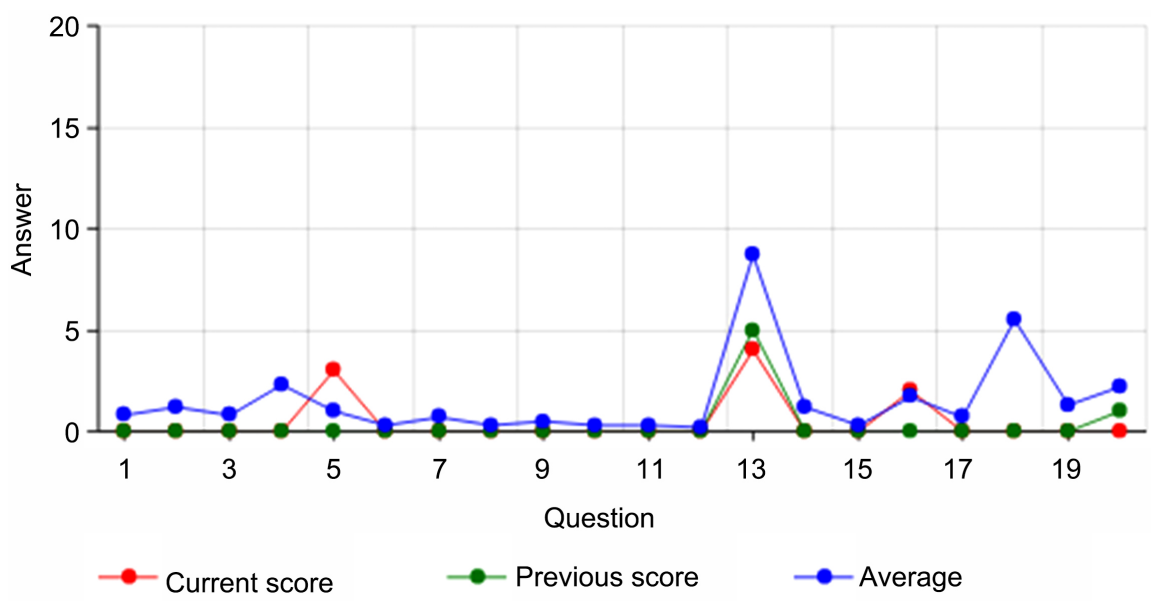

Figure 6. Defense routines graphic representing a numerical value (current \& historical) on a scale illustrating the degree of defense routines or defensiveness by an employee. ( 0 $100)=$ Very Low Defense Routines, $(101-200)=$ Low Defense Routines, $(201-300)=$ Moderate to High Defense Routines, $(301-371)=$ High Defense Routines, and (371 400) $=$ Extremely High Defensive Routines.

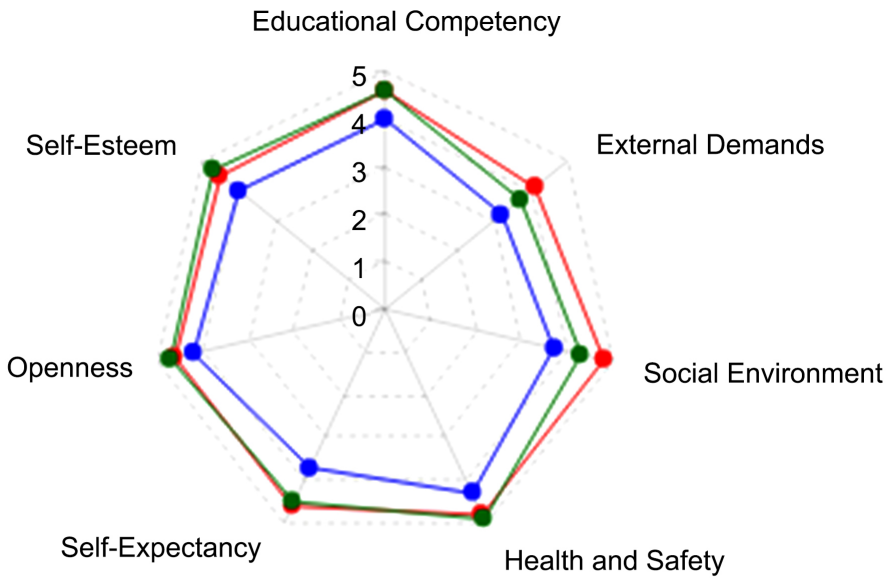

Current Assessment

Previous Assessment

Average Assessment

Figure 7. PMP graphic representing a numerical value (current, last and mean) on a scale illustrating the degree of adaptability. $(0$ - 175) = Extremely Low Adaptability, (176 - 325) = Very Low Adaptability, (326 - 500) = Low Adaptability, (501 - 775) = Adaptable, (776 $850)=$ Good Adaptability, and $(851-1000)=$ Highly Adaptable. A uniformed round PMP Spider-gram represents an optimal and preferred situational balance.

\section{Derivative Assessments (Extracted from the EFP Assessment Questions)}

Three derivative assessments are extracted from the original 110 EFP questions: a Risk for Burnout, a Risk for Anxiety, and a Risk for Depression. A fourth assessment called the Engagement Potential is derived from the three abovementioned.

The Risk for Burnout has 30 questions that make up the risk assessment. They are compiled from the EFP Batch of questions as follows: (5) Motivation, (5) 
Stress, (5) Defense Routines, (0) Knowledge, (6) PMP-External Demands, (0) Social Environment, (2) Health and Safety, (3) Self-Expectancy, (0) Openness, and (2) Self-Esteem.

The Risk for Anxiety has 20 questions that make up the risk assessment. They are compiled from the EFP Batch of questions as follows: (0) Motivation, (5) Stress, (3) Defense Routines, (0) Knowledge, (1) PMP-External Demands, (1) Social Environment, (6) Health and Safety, (2) Self-Expectancy, (1) Openness, and (1) Self-Esteem.

The Risk for Depression has 20 questions that make up the risk assessment. They are compiled from the EFP Batch of questions as follows: (1) Motivation, (1) Stress, (5) Defense Routines, (0) Knowledge, (0) PMP-External Demands, (4) Social Environment, (4) Health and Safety, (3) Self-Expectancy, (1) Openness, and (2) Self-Esteem.

The Engagement Potential measure is calculated from the mean of means from the Burnout, Anxiety and Depression values. The purpose of this assessment is to measure and individual's engagement potential. This should not be confused with an individual's motivation, stress, or PMP levels. Engagement Potential is a composite of the measure above and the values are reversed into five (5) levels: (5 = M vales < 3.499) Very Poor Engagement Potential, (4 = Mean values from 3.500 - 6.499) Low Engagement Potential, ( 3 = Mean values from 6.500 - 8.999) Moderate Engagement Potential, ( 2 = Mean values from 9.00 10.999) High Engagement Potential, and ( $1=$ Mean values $>11.000)$ Excellent Engagement Potential.

\subsection{Ethical Statement, Procedures for Assessment Collection and Data Analyses}

Ethical approval was received from the University of Lund ethics committee.

Data was extrapolated from organizations in the My-E-Health program. All employees had agreed to co-ownership of the data and to participate in research. All individuals have approved our GPDS regulations and responsibilities and are currently or were members of our Company Healthcare program. Seventy-three $(\mathrm{N}=73)$ employees took 119 batches of EFP assessments. However, for the purpose of this paper only the first assessment for each will be used. Employees were informed about ongoing research and the objectives of the studies, anonymity, and confidentiality of the survey.

Since all assessed individuals entering the My-E-Health EFP platform are unknown (as little information was known about them prior to their assessments, no pre-qualifications or demographics are applied, and no individual categorization or adjustments are made) they should be considered one large cohort. There is only one contingency, all assessed persons within this study were fulltime employees. Their assessments were subjective and purely based upon how the individual interprets their own situational environment, health, and wellbeing. Personal data are strictly kept private between the individuals and their counselors/ 
caregivers. No information was made available to employer organizations other than aggregate data pertaining to their company.

This study evaluates both the reliability of the assessments to provide consistent data and the validity to delivery useful real-life values for real-world applications and preventive measures. No previously reported information for this measure is available, separate confirmatory factor analyses were first performed after the batch of assessments was taken and only during the feedback session, one to one with a counselor, and only after results were presented to the individual.

\section{Results}

Results are organized into three sections: Reliability, Internal Validity using Discriminant statistics, External Validity where correlations to real-life pre-diagnosis and pharmaceutical prescriptions were consumed. All results were calculated using IBM SPSS and according to required principles.

\subsection{Reliability}

EFP batch of assessments was analyzed using Cronbach's Alpha for internal consistency where an $\alpha \geq 0.70$ is considered acceptable, $\alpha \geq 0.80$ is considered good, and an $\alpha \geq 0.90$ is considered excellent.

Results showed Motivation (Items $=20, \alpha=0.939$ ), Stress (Items $=20, \alpha=$ 0.887), Defense Routines (Items $=20, \alpha=0.870$ ), and PMP (Items $=50, \alpha=$ 0.944 ) all with significant reliability.

General frequency statistics (Figure 8) show normal distributions and ranges in relation to what would be normally expected where zero (0) is the minimum (low) and twenty (20) is maximum mean value. High Motivation and high PMP values are considered good, whereas high Stress and high Defense Routines are considered poor. The distribution Skewness (Figure 8) and Standard Canonical Discriminant Function Coefficients spread (Figure 9) for each of the assessments confirms this clearly.

\subsection{Internal Validity Using Discriminant Statistics}

Internal Validity using Discriminant statistics showed breadth of the EFP batch of assessment with significant reliability and validity. Predicted Group Membership classifications were conducted on the four EFP based assessments:

1) Motivation (95.9\% of original grouped cases were correctly classified, and 93.2\% of cross-validated grouped cases were correctly classified, Effect Size .881, Wilks' Lambda 0.106, $p<0.001$ ) and good Group Centroid Separations from Low Motivation to Highly Motivated were noted.

2) Stress (91.8\% of original grouped cases were correctly classified, and $89.0 \%$ of cross-validated grouped cases were correctly classified, Effect Size 0.913, Wilks' Lambda 0.072, $p<0.001$ ) and good Group Centroid Separations from Low Stress to Highly Stressed were noted. 


\begin{tabular}{|c|c|c|c|c|c|}
\hline & & & stics & & \\
\hline & & $\begin{array}{c}\text { Motivation } \\
\text { (Mean) }\end{array}$ & $\begin{array}{l}\text { Stress } \\
\text { (Mean) }\end{array}$ & $\begin{array}{c}\text { Defense } \\
\text { Routines } \\
\text { (Mean) }\end{array}$ & $\begin{array}{l}\text { PMP } \\
\text { (Mean) }\end{array}$ \\
\hline & Valid & 73 & 73 & 73 & 73 \\
\hline & Missing & 0 & 0 & 0 & 0 \\
\hline Mean & & 15.2151 & 5.0562 & 3.9685 & 14.6301 \\
\hline Median & & 15.7000 & 4.4000 & 3.9000 & 15.0000 \\
\hline Std. Deviati & & 3.03378 & 2.80862 & 2.45599 & 2.51538 \\
\hline Variance & & 9.204 & 7.888 & 6.032 & 6.327 \\
\hline Skewness & & -1.071 & 0.715 & 0.455 & -0.572 \\
\hline Std. Error of & kewness & 0.281 & 0.281 & 0.281 & 0.281 \\
\hline Range & & 14.10 & 11.90 & 10.70 & 10.30 \\
\hline & 25 & 13.7000 & 3.0500 & 2.0500 & 13.1000 \\
\hline Percentiles & 50 & 15.7000 & 4.4000 & 3.9000 & 15.0000 \\
\hline & 75 & 17.4500 & 6.6500 & 5.8000 & 16.2500 \\
\hline
\end{tabular}

Figure 8. Shows expected mean and percentile rates for the four EFP assessments indicating high median values for Motivation and PMP (adaptability) and low median values for both Stress and Defense Routines.

\section{Standardized Canonical Discriminant Function Coefficients} Function

\begin{tabular}{lc|c|c} 
& 1 & 2 & 3 \\
\hline M mean & 1.175 & 0.135 & 0.230 \\
\hline S mean & -0.203 & -0.150 & 1.325 \\
\hline D mean & 0.134 & 1.088 & -0.019 \\
\hline PMP mean & -0.440 & -0.010 & 0.842 \\
\hline
\end{tabular}

Figure 9. Shows a good spread for each of the four EFP assessments indicating expected Canonical Discriminant Function Coefficients. $M=$ Motivation, $S=$ Stress, $D=$ Defense Routines, PMP $=$ Perpetual Motivation Positioning.

3) Defense Routines (97.3\% of original grouped cases were correctly classified, and $94.5 \%$ of cross-validated grouped cases were correctly classified, Effect Size 0.891, Wilks' Lambda 0.103, $p<0.001$ ) and good Group Centroid Separations from Low Defense Routines to Moderate Defense Routines were noted; PMP (100\% of original grouped cases were correctly classified, and $97.3 \%$ of cross-validated grouped cases were correctly classified, Effect Size 0.908, Wilks' Lambda 0.084, $p<0.001$ ) and good Group Centroid Separations from Low Adaptability to High Adaptability.

\subsection{External Validity}

An external validity construct was established, by asking employees (during their feedback session) a dichotomous (yes/no) and an accuracy (0 - 100) question 
regarding how they really felt in relation to the assessment results. Sometimes during a counseling session, it is easy to forget to ask employees the dichotomous and accurate questions. Of the seventy-three $(\mathrm{N}=73)$ a total of seventy $(70)$ individuals were asked the validation question (Figure 10) resulting in a 0.885 percent accuracy.

A frequency analysis for Anti-Depressive prescription use confirmed that three (3) or $4.1 \%$ of population consumed anti-depressive medications (Figure 11). Further investigation using a nonparametric correlation into the use of anti-depressive medications and any previously known diagnosis for High Stress, Anxiety, Depression or Burnout showed a significant correlation $p \leq 0.001$ confirming external validity and the ability of the EFP to correctly set risk levels. Coefficient using Kendall's tau_b and Spearman's rho (Figure 12) was used to analyze medical prescription (anti-depressives) use for a mental health diagnosis or treatment for stress or burnout $(p<0.001)$.

\begin{tabular}{|c|c|c|c|c|}
\hline & & Statist & & \\
\hline & & $\begin{array}{c}\text { Engagement } \\
\text { Accuracy }\end{array}$ & $\begin{array}{c}\text { EFP Feedback } \\
\text { Validity }\end{array}$ & Accuracy \\
\hline & Valid & 64 & 70 & 66 \\
\hline & Missing & 9 & 3 & 7 \\
\hline Mean & & 0.8930 & 88.50 & 88.64 \\
\hline Median & & 0.9000 & 90.00 & 90.00 \\
\hline Std. Deviatic & & 0.07230 & 7.535 & 7.968 \\
\hline Variance & & 0.005 & 56.775 & 63.497 \\
\hline Skewness & & -2.283 & -1.195 & -1.676 \\
\hline Std. Error of & ewness & 0.299 & 0.287 & 0.295 \\
\hline Range & & 0.40 & 40 & 40 \\
\hline & 25 & 0.9000 & 85.00 & 90.00 \\
\hline Percentiles & 50 & 0.9000 & 90.00 & 90.00 \\
\hline & 75 & 0.9000 & 91.25 & 90.00 \\
\hline
\end{tabular}

Figure 10. A frequency table showing verbal employee to counselor feedback regarding the accuracy and correctness of the assessment graph shown to the employee.

\begin{tabular}{ll|r|r|r|r}
\multicolumn{7}{c}{} & \multicolumn{2}{c}{ Anti-Depressive Medication Use } & \\
& & Frequency & Percent & Valid Percent & $\begin{array}{c}\text { Cumulative } \\
\text { Percent }\end{array}$ \\
\hline \multirow{3}{*}{ Valid } & Yes & 3 & 4.1 & 4.3 & 4.3 \\
\cline { 2 - 6 } & No & 66 & 90.4 & 95.7 & 100.0 \\
\cline { 2 - 6 } & Total & 69 & 94.5 & 100.0 & \\
\hline Missing & System & 4 & 5.5 & & \\
\hline Total & & 73 & 100.0 & & \\
\hline
\end{tabular}

Figure 11. Table shows that $4.3 \%$ ( 3 of $\mathrm{N}=73$ ) were taking anti-depressive medications when they first took the EFP batch of assessments. 
Although not an objective in this study, a hypothesis of Gender (Figure 13) differences has been rejected for mean scores in Motivation $(p>0.864)$, Stress $(p>0.345)$, Defense Routines $(p>0.891)$, and PMP $(p>0.310)$. Statistical correlations showed little deviations between Gender and Age. Further evaluation using a Pearson correlation coefficient ( $r$ is 0.1 to $0.3=$ Small, 0.3 to $0.50=\mathrm{Me}$ dium, and 0.5 to $1.0=$ Large) showed no correlations with age in Motivation ( $r=$ $0.083, p<0.484)$, Stress $(r=-0.061, p<0.611)$, Defense Routines $(r=-0.157, p$ $<0.186)$, and PMP $(r=0.079, p<0.504)$.

\section{Correlations}

\begin{tabular}{|c|c|c|c|c|}
\hline & & & $\begin{array}{c}\text { Anti-Depressive } \\
\text { Use }\end{array}$ & $\begin{array}{c}\text { Stress or Burnout } \\
\text { Diagnosis }\end{array}$ \\
\hline \multirow{6}{*}{$\begin{array}{l}\text { Kendall's } \\
\text { tau_b }\end{array}$} & \multirow{3}{*}{$\begin{array}{l}\text { Anti-Depressive } \\
\text { Use }\end{array}$} & Correlation Coefficient & 1.000 & $0.652^{\star *}$ \\
\hline & & Sig. (2-tailed) & . & 0.000 \\
\hline & & $\mathrm{N}$ & 69 & 69 \\
\hline & \multirow{3}{*}{$\begin{array}{l}\text { Stress or Burnout } \\
\text { Diagnosis }\end{array}$} & Correlation Coefficient & $0.652^{* \star}$ & 1.000 \\
\hline & & Sig. (2-tailed) & 0.000 & . \\
\hline & & $\mathrm{N}$ & 69 & 69 \\
\hline \multirow{6}{*}{$\begin{array}{l}\text { Spearman's } \\
\text { rho }\end{array}$} & \multirow{3}{*}{$\begin{array}{l}\text { Anti-Depressive } \\
\text { Use }\end{array}$} & Correlation Coefficient & 1.000 & $0.652^{* *}$ \\
\hline & & Sig. (2-tailed) & . & 0.000 \\
\hline & & $\mathrm{N}$ & 69 & 69 \\
\hline & \multirow{3}{*}{$\begin{array}{l}\text { Stress or Burnout } \\
\text { Diagnosis }\end{array}$} & Correlation Coefficient & $0.652^{*+*}$ & 1.000 \\
\hline & & Sig. (2-tailed) & 0.000 & . \\
\hline & & $\mathrm{N}$ & 69 & 69 \\
\hline
\end{tabular}

"Correlation is significant at the 0.01 level (2-tailed).

Figure 12. Table shows a significant correlation between the use of anti-depressive medications and a stress or burnout score in the EFP batch of assessments.

\section{Group Statistics T-Test}

\begin{tabular}{|c|c|c|c|c|c|}
\hline & Gender & $\mathrm{N}$ & Mean & Std. Deviation & Std. Error Mean \\
\hline \multirow{2}{*}{ Motivation (Means) } & Male & 33 & 15.4727 & 3.06158 & 0.53295 \\
\hline & Female & 40 & 15.0025 & 3.03285 & 0.47954 \\
\hline \multirow{2}{*}{ Stress (Means) } & Male & 33 & 5.2576 & 3.08333 & 0.53674 \\
\hline & Female & 40 & 4.8900 & 2.58842 & 0.40926 \\
\hline \multirow{2}{*}{$\begin{array}{l}\text { Defense Routines } \\
\text { (Means) }\end{array}$} & Male & 33 & 4.3030 & 2.49656 & 0.43460 \\
\hline & Female & 40 & 3.6925 & 2.41845 & 0.38239 \\
\hline \multirow{2}{*}{ PMP (Means) } & Male & 33 & 14.6515 & 2.67992 & 0.46651 \\
\hline & Female & 40 & 14.6125 & 2.40568 & 0.38037 \\
\hline
\end{tabular}

Figure 13. Shows good homogeneity in gender. 


\subsection{Derivative Assessments (Extracted from the EFP Assessment Questions)}

Discriminant statistical analysis was done on the Derivate Reports (those risk assessments extrapolated from the EFP Batch of Assessments) for Burnout, Anxiety, Depression and Engagement Potential also resulted in statistically significant results supporting both validity and reliability. Although not part of this intended study, the findings were of added value it was decided to include these in a brief synopsis herewith:

Risk for Burnout

Burnout $(\alpha=0.943, \mathrm{M}=5.77, \mathrm{SD}=2.976, \mathrm{~N}=73$ ) showed normal distribution with no outliers. A discriminant analysis of Risk for Burnout shows excellent results with no missing or out-of-range codes, groups, or variables $(p<$ $0.001)$. Tests of Equality of Group Means were statistically significant $(p<$ 0.001). Canonical Discriminant Functions show a Canonical Correlation of 0.954 and an excellent Effect Size of 0.910 . Wilks' Lambda is significantly significant $(p<0.001)$ with a correlational structure matrix $(0.913)$ which is larger than the minimum desired (0.3). Canonical Function Coefficients showed good separation: (No Evidence of Burnout (-4.151), Low Risk for Burnout (-0.921), Moderate Risk for Burnout (2.998), and High Risk for Burnout (6.085). Classification statistics for Predicated Group Membership resulted in the following percentages for No Evidence of Burnout (100\%), Low Risk for Burnout (94.1\%), Moderate Risk for Burnout (94.1\%), and High Risk for Burnout (100\%). Analysis showed that $95.9 \%$ of original grouped cases were correctly classified. $94.5 \%$ of cross-validated grouped cases were also correctly classified.

Risk of Anxiety

Anxiety ( $\alpha=0.864, \mathrm{M}=5.18, \mathrm{SD}=2.858, \mathrm{~N}=73$ ) showed normal distribution with no outliers. A discriminant analysis of Risk for Anxiety shows excellent results with no missing or out-of-range codes, groups, or variables $(p<0.001)$. Tests of Equality of Group Means were statistically significant $(p<0.001)$. Canonical Discriminant Functions show a Canonical Correlation of 0.816 and an acceptable Effect Size (0.665). Wilks' Lambda is significantly significant $(p<$ 0.001 ) with a correlational structure matrix $(0.986)$ which is larger than the minimum desired (0.3). Canonical Function Coefficients showed good separation: Low Risk of Anxiety (-0.734), Moderate Risk of Anxiety (2.056), and High Risk of Anxiety (4.107). Classification statistics for Predicated Group Membership resulted in the following percentages: Low Risk of Anxiety (92.9\%), Moderate Risk of Anxiety (85.7\%), and High Risk of Anxiety (100\%). Analysis showed that $91.8 \%$ of original grouped cases were correctly classified. $84.3 \%$ of cross-validated grouped cases were also correctly classified.

Risk for Depression

Burnout ( $\alpha=0.798, \mathrm{M}=5.11, \mathrm{SD}=2.389, \mathrm{~N}=73$ ) showed normal distribution with no outliers. A discriminant analysis of Risk for Depression shows excellent results with no missing or out-of-range codes, groups, or variables $(p<$ 
0.001). Tests of Equality of Group Means were statistically significant $(p<$ 0.001). Canonical Discriminant Functions show a Canonical Correlation of 0.723 and an acceptable Effect Size (0.522). Wilks' Lambda is significantly significant $(p<0.001)$ with a correlational structure matrix $(0.965)$ which is larger than the minimum desired (0.3). However, Canonical Function Coefficients showed good separation: Low Risk for Depression (-0.475), Moderate Risk for Depression (2.124), and High Risk for Depression (2.984). Classification statistics for Predicated Group Membership resulted in the following percentages: Low Risk Depression (85\%), Moderate Risk for Depression (100\%), and High Risk for Depression (100\%). Analysis showed that $87.7 \%$ of original grouped cases were correctly classified. $84.9 \%$ of cross-validated grouped cases were also correctly classified.

Engagement Potential

Engagement Potential Assessment ( $\alpha=0.959, \mathrm{M}=3.849, \mathrm{SD}=0.967$, Var $=$ 0.935) showed normal distribution with no outliers. It is compiled from the mean of means from the Burnout, Anxiety and Depression values. A lineal Univariate Anova Analysis of the variance using a Criteria = Alpha (0.05) $(\mathrm{N}=73)$ between the Dependent variable Engagement and Burnout $(p<0.001$, Partial Eta Squared $=0.953$, Cohen's $d=0.952)$, Anxiety $(p<0.001$, Partial Eta Squared $=$ 0.974, Cohen's d =0.974), Depression $(p<0.001$, Partial Eta Squared 0.951, Cohen's $d=0.950)$ showed statistically significant results with excellent effect size and reliability $(\alpha=0.959)$.

Engagement Potential was also measured against the basic four EFP batch assessments using a Pearson correlation coefficient (where $r$ is 0.1 to $0.3=$ Small, 0.3 to $0.50=$ Medium, and 0.5 to $1.0=$ Large) that showed good correlations with Engagement Potential for Motivation $(r=0.735, p<0.001, \mathrm{M}=15.21, \mathrm{SD}=$ 3.03), Stress $(r=0.809, p<0.001, \mathrm{M}=5.05, \mathrm{SD}=2.80)$, Defense Routines $(r=$ $0.656, p<0.001, \mathrm{M}=9.96, \mathrm{SD}=2.45)$, and PMP $(r=0.910, p<0.001, \mathrm{M}=14.63$, $\mathrm{SD}=2.51)$.

\section{Discussion}

The EFP batch has shown excellent reliability and validity with significantly significant correlations in relation to the various risk assessments. Evidence showed clear negative correlations between an employee's Engagement Potential and their Risk for Burnout, Risk for Anxiety, Risk for Depression.

EFP was analyzed using Cronbach's Alpha for internal consistency, where an $\alpha \geq 0.70$ is considered acceptable, $\alpha \geq 0.80$ is considered good, and an $\alpha \geq 0.90$ is considered excellent. Results $(\mathrm{N}=73)$ showed that all sub assessments had good to excellent alpha coefficient scores: Motivation (Items $=20, \alpha=0.939$ ), Stress (Items $=20, \alpha=0.887$ ), Defense Routines (Items $=20, \alpha=0.870$ ), and PMP (Items $=50, \alpha=0.944)$.

A multivariate was used to test a null hypothesis that the error variance of the dependent variable is equal across the groups using Risk for Burnout mean as a 
Dependent variable. $\mathrm{H}_{0}$ cannot be rejected (Motivation $(p \leq 0.001$, Partial Eta Squared $=0.886)$, Stress $(p \leq 0.001$, Partial Eta Squared $=0.946)$ and PMP $(p<$ 0.001; Partial Eta Squared $=0.921)$ and Defense Routines $(p<0.019$, Partial Eta Squared $=0.838$ ).

The use of aggregate company of department data to show historical, current and trends in employee risk, engagement and sustainability could also serve to support organizational strategic planning, leadership training and proactive transformational change objectives. Figures 14-17 illustrate a typical histogram with a distribution curve overlay for Motivation and PMP, where high values are good, and for Stress and Defense Routines, where low values are good.

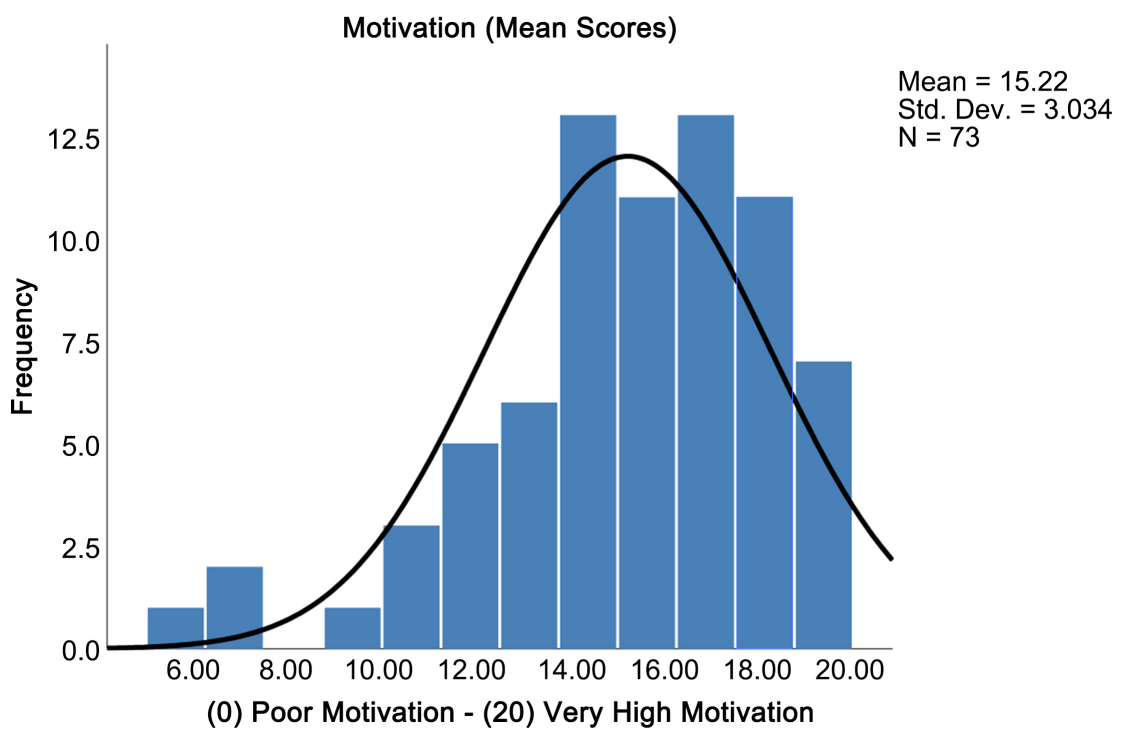

Figure 14. Show a histogram with a distribution curve for group motivation $(M=15.22$, $\mathrm{SD}=3.034, \mathrm{~N}=73$ ).

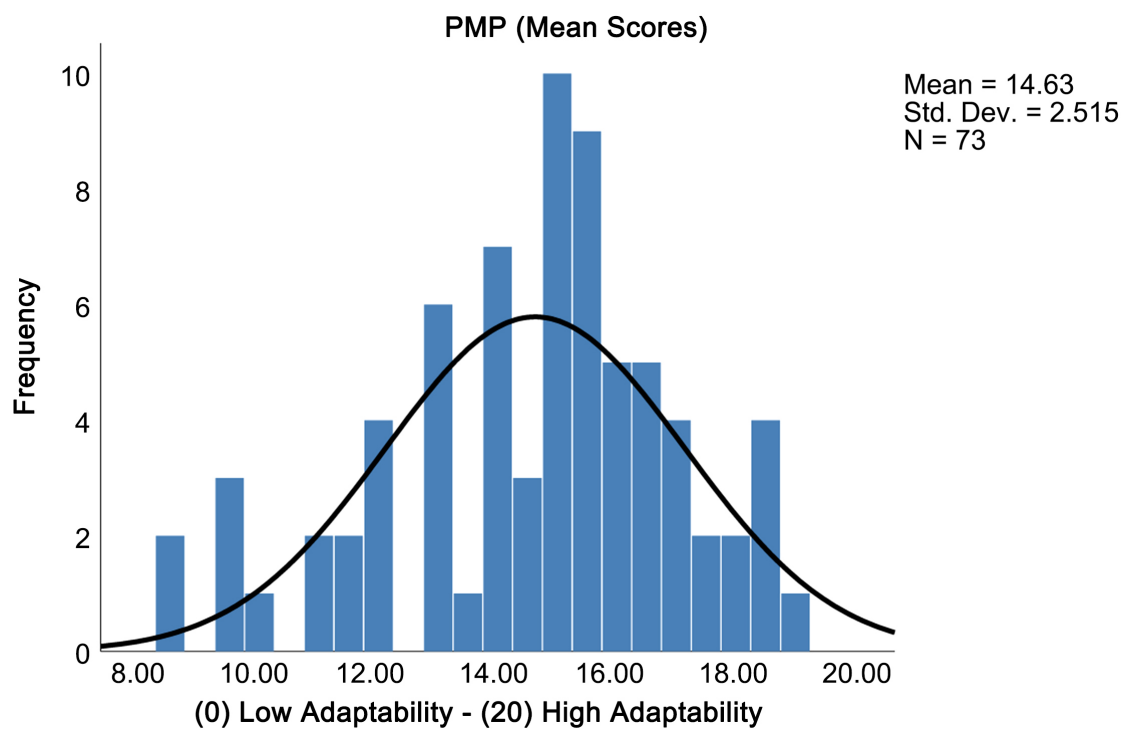

Figure 15. Show a histogram with a distribution curve overlaid for PMP (M = 14.63, SD $=2.515, \mathrm{~N}=73$ ). 


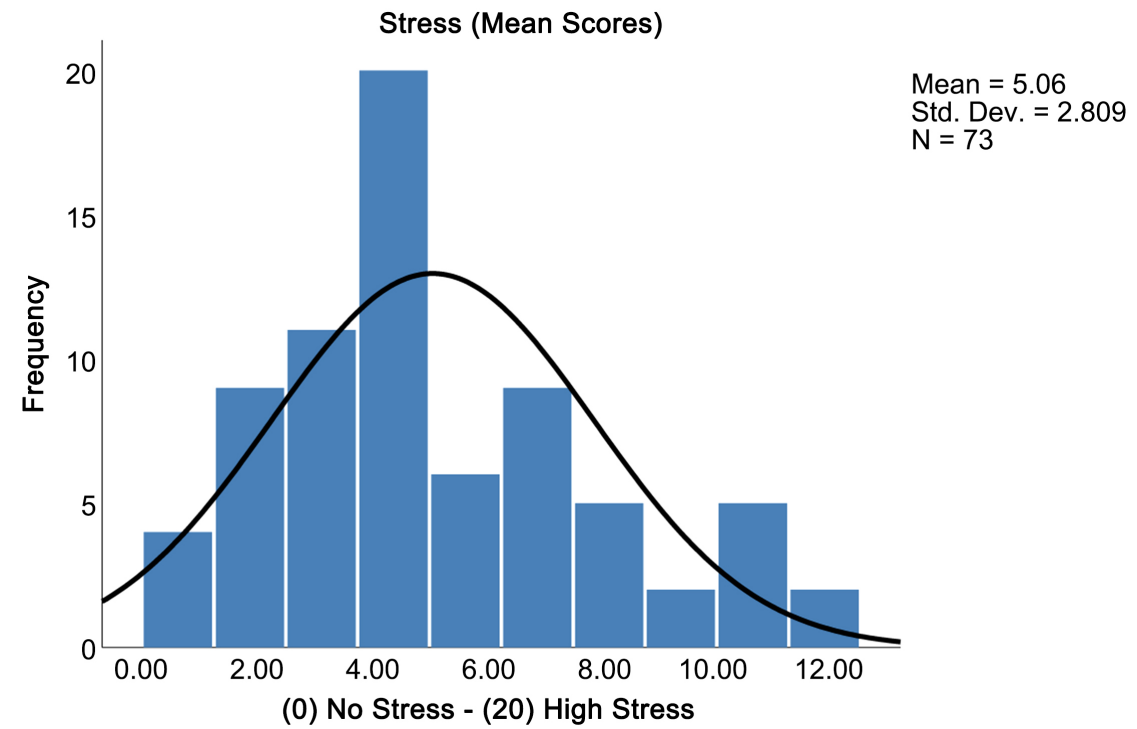

Figure 16. Show a histogram with a distribution curve overlaid for stress $(M=5.06, S D=$ $2.809, \mathrm{~N}=73)$.

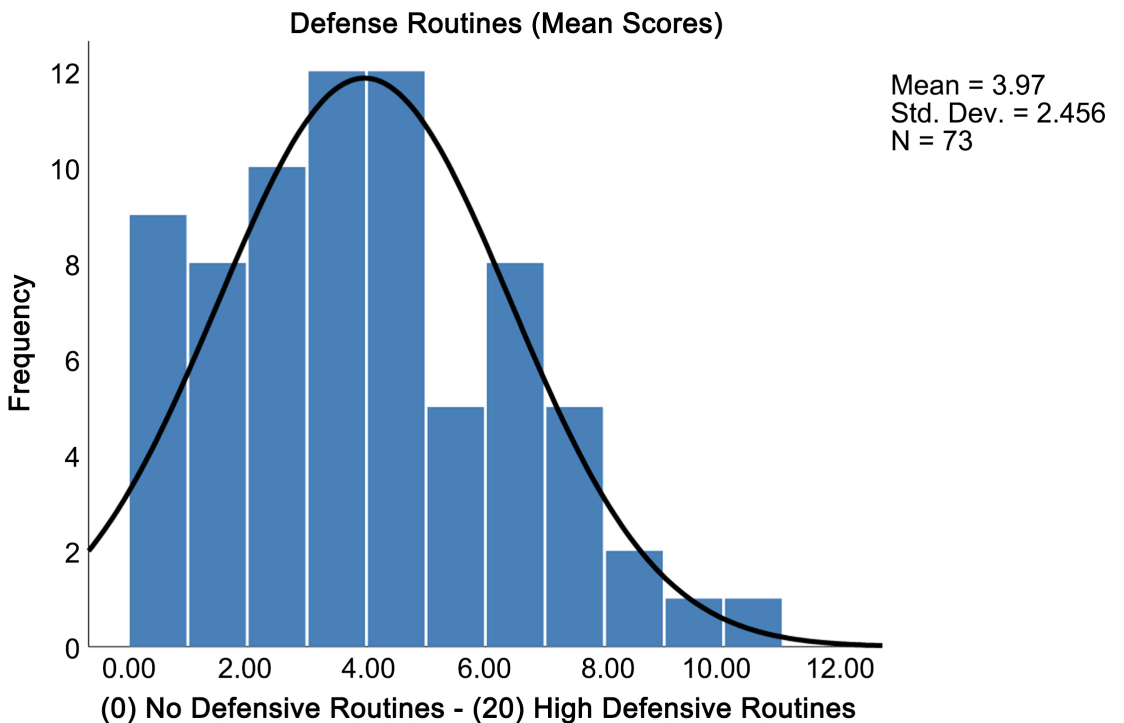

Figure 17. Show a histogram with a distribution curve overlaid for defense $(M=3.97, S D$ $=2.456, \mathrm{~N}=73$ ).

Further evaluation provides an overview of internal and situational constraints or hinders facing an individual or larger groups. If used correctly, coaches, therapists, psychologists, and medical personnel can effectively reduce costs by proactively engaging with their clients. The benefit with the EFP batch is that intervention can begin at an early phase when psychosocial challenges are identified. This alone will reduce both the cost and effort needed to prevent a "slippery slope effect" into work-related mental ill-health. Notwithstanding, this tool can also be used retroactively to monitor progression of an individual's treatment or even as an actionable plan for treatment programs based upon how an individual interprets their situational needs rather than a generic "one fits all 
solution." Therefore, a broader use of the EFP batch as a measure of psychosocial situational wellbeing is highly plausible.

\section{Conclusion}

Psychology has seen an increased need for such things as meaning, self-care, mindfulness, meditation, work-life balance, and other mechanisms designed to address human sustainability in the workplace. So, we might ask ourselves, why is there a world-wide mental health epidemic costing more than $\$ 738$ billion annually?

One of the reasons is the psychological safety disconnect between an individual's situational wellbeing and organizational accountability. Retroactive and symptom-based solutions are only temporary plasters as they do not address the foundation of psychological safety needs and cannot be used productively in prevention initiatives.

A positive outcome of this reliability and validity study highlights the value of a risk assessment in relation to Burnout, Anxiety, Depression and how the EFP batch methodology can be adopted to measure and prevent occupational mental health related illnesses. Furthermore, this study revealed a novel measure for employee Engagement Potential. Sustainability after all is not just about the environment but the people within it too.

Any solution that raises self-awareness and leads the way towards effective dialog is a positive step forward. Nonetheless, when a novel and scalable method can proactively measure, identify, and align with cognitional theory to stave-off unnecessary mental health afflictions, it has the potential to be adopted by companies on a worldwide basis. Since diagnosis is not the primary objective here, but rather the proactive methodology to engage with employees, and to assist them in understanding and managing their own personal situational environments, the EFP Batch of assessments has shown to be reliable, viable and worthy of additional research in some larger international organizations.

\section{Conflicts of Interest}

The author declares no conflicts of interest regarding the publication of this paper.

\section{References}

Abend, R., Dan, O., Maoz, K., Raz, S., \& Bar-Haim, Y. (2014). Reliability, Validity and Sensitivity of a Computerized Visual Analog Scale Measuring State Anxiety. Journal of Behavior Therapy and Experimental Psychiatry, 45, 447-453. https://people.socsci.tau.ac.il/mu/anxietytrauma/files/2014/04/Abend-et-al-2014-JBTE P.pdf https://doi.org/10.1016/j.jbtep.2014.06.004

Admasachew, L., \& Dawson, J. (2011). The Association between Presenteeism and Engagement of National Health Service Staff. Journal of Health Services Research \& Policy, 16, 29-33. https://doi.org/10.1258\%2Fjhsrp.2010.010085 
Alvesson, M. (2004). Knowledge Work and Knowledge-Intensive Firms. Oxford: Oxford University Press.

Anitha, J. (2014). Determinants of Employee Engagement and Their Impact on Employee Performance. International Journal of Productivity and Performance Management, 63, 308-323. https://doi.org/10.1108/IJPPM-01-2013-0008

Baumruk, R. (2004). The Missing Link: The Role of Employee Engagement in Business Success. Workspan, 47, 48-52.

Bennett, R. J., \& Robinson, S. L. (2000). Development of a Measure of Workplace Deviance. The Journal of Applied Psychology, 85, 349-360.

https://doi.apa.org/doi/10.1037/0021-9010.85.3.349

Business in the Community-Charity (2019). Time to Take Ownership, Mental Health at Work. London: Business in the Community-Charity. https://www.bitc.org.uk/wp-content/uploads/2019/10/bitc-wellbeing-report-mentalhea lthatwork2019scotlandfocus-oct19.pdf

Cahill, J. (1996). Psychosocial Aspects of Interventions in Occupational Safety and Health. American Journal of Industrial Medicine, 29, 308-313. https://doi.org/10.1002/(SICI)1097-0274(199604)29:4\%3C308::AID-AJIM6\%3E3.0.CO; $\underline{2-\mathrm{K}}$

Collins, J. J., Baase, C. M., Sharda, C. E.., Ozminkowski, R. J., Nicholson, S., Billotti, G. M, Turpin, R. S., Olson, M., \& Berger, M. L. (2005). The Assessment of Chronic Health Conditions on Work Performance, Absence, and Total Economic Impact for Employers. Journal of Occupational and Environmental Medicine, 47, 547-557. https://doi.org/10.1097/01.jom.0000166864.58664.29

Deloitte. (2020). Mental Health and Employers Safety at Work: Refreshing the Case for Investment.

https://www2.deloitte.com/content/dam/Deloitte/uk/Documents/consultancy/deloitteuk-mental-health-and-employers.pdf

Duijts, S. F., Kant, I., Swaen, G. M., van den Brandt, P. A., \& Zeegers, M. P. (2007). A Meta-Analysis of Observational Studies Identifies Predictors of Sickness Absence. Journal of Clinical Epidemiology, 60, 1105-1115. https://doi.org/10.1016/j.jclinepi.2007.04.008

Freud, S. (1923). The Ego and the ID. https://www.sigmundfreud.net/the-ego-and-the-id-pdf-ebook.jsp

HSE (Health Safety Executive) (2019). Health and Safety at Work: Summary Statistics for Great Britain 2019. https://www.hse.gov.uk/statistics/overall/hssh1819.pdf

ILO (International Labor Organization) (2020). Employment Worldwide. ilo.org.

Israel, B. A., Baker, E. A., Goldenhar, L. M., Heaney, C. A., \& Schurman, S. J. (1996). Occupational Stress, Safety, and Health: Conceptual Framework and Principles for Effective Prevention Interventions. Journal of Occupational Health Psychology, 1, 261-286. https://doi.apa.org/doi/10.1037/1076-8998.1.3.261

Janssens, H., Clays, E., de Clercq, B., de Bacquer, D., Casini, A., Kittel, F., \& Braeckman, L. (2016). Association between Psychosocial Characteristics of Work and Presenteeism: A Cross-Sectional Study. International Journal of Occupational Medicine and Environmental Health, 29, 331-344. https://doi.org/10.13075/ijomeh.1896.00588

Kessler, R. C., Barber, C., Beck, A., Berglund, P., Cleary, P. D., McKenas, D., Pronk, N., Simon, G., Stang, P., Ustun, T. B., \& Wang, P. (2003). The World Health Organization Health and Work Performance Questionnaire (HPQ). Journal of Occupational Environmental Medicine, 45, 156-174. https://doi.org/10.1097/01.jom.0000052967.43131.51

Kinman, G. (2019). Sickness Presenteeism at Work: Prevalence, Costs and Management. 
British Medical Bulletin, 129, 69-78. https://doi.org/10.1093/bmb/ldy043

Koopmans, L., Coffeng, J. K., Bernaards, C. M., Boot, C. R. L., Hildebrandt, V. H., de Vet, H. C. W. et al. (2014). Responsiveness of the Individual Work Performance Questionnaire. BMC Public Health, 14, Article No. 513. https://doi.org/10.1186/1471-2458-14-513

McManus, S., Bebbington, P., Jenkins, R., \& Brugha, T. (2016). Mental Health and Wellbeing in England: Adult Psychiatric Morbidity Survey 2014 [Internet]. https://assets.publishing.service.gov.uk/government/uploads/system/uploads/attachme nt data/file/556596/apms-2014-full-rpt.pdf

Michelsen, C. S. (2008). Management by Cross-Training (295 p). Charleston, SC: Book Surge Publishing.

Michelsen, C. S., \& Thorsteinsdottir, H. H. (2010). Defensive Routines and Their Origins (81 p). Master Thesis, Lund: University of Lund.

Michelsen, C.S. (2019). Preventing Burnout. https://www.my-e-health.se/blog/post/81

Michie, S., \& Williams, S. (2003). Reducing Work Related Psychological Ill Health and Sickness Absence: A Systematic Literature Review. Occupational and Environmental Medicine, 60, 3-9. https://doi.org/10.1136/oem.60.1.3

Mnookin, S. (2016). Out of the Shadows: Making Mental Health a Global Development Priority. Geneva: World Bank and World Health Organization.

https://www.who.int/mental health/advocacy/wb background paper.pdf

Morgan, G. (1997). Images of Organization (2nd ed.). London: Sage Publications.

Neisser, U. (1967). Cognitive Psychology. Appleton-Century-Crofts.

Salvagioni, D. A. J., Melanda, F. N., Mesas, A. E., González, A. D., Gabani, F. L., \& Andrade, S. M. (2017). Physical, Psychological and Occupational Consequences of Job Burnout: A Systematic Review of Prospective Studies. PLoS ONE, 12, e0185781. https://doi.org/10.1371/journal.pone.0185781

Schaufeli, W. B., Salanova, M., González-Romá, V., \& Bakker, A. B. (2002). The Measurement of Engagement and Burnout: A Confirmative Analytic Approach. Journal of Happiness Studies, 3, 71-92. https://doi.org/10.1023/A:1015630930326

Senge, P. M. (1990). The Fifth Discipline. London: Century Business.

Skagen, K., \& Collins, A. M. (2016). The Consequences of Sickness Presenteeism on Health and Wellbeing over Time: A Systematic Review. Social Science \& Medicine, 161, 169-177. https://doi.org/10.1016/j.socscimed.2016.06.005

Skandia (2019). Sverige förlorar 64 miljarder på sjukskrivningar. https://www.skandia.se/om-oss/nyheter/nyhetsarkiv/2019/sverige-forlorar-64-miljarde r-pa-sjukskrivningar---psykisk-ohalsa-star-for-varannan-diagnos/

Smith, P., \& Beaton, D. (2008). Measuring Change in Psychosocial Working Conditions: Methodological Issues to Consider When Data Are Collected at Baseline and One Follow-Up Time Point. Occupational and Environmental Medicine, 65, 288-296. https://doi.org/10.1136/oem.2006.032144

Williams, L. J., \& Anderson, S. E. (1991). Job Satisfaction and Organizational Commitment as Predictors of Organizational Citizenship and In-Role Behaviors. Journal of Management, 17, 601-617. https://doi.org/10.1177/014920639101700305 